\title{
Mathematical Modelling of Wastewater Collection System in Cha-Am Municipality using PCSWMM
}

\author{
Thawtar Htun ${ }^{1}$, Kim N. Irvine ${ }^{2}$, Ranjna Jindal ${ }^{3}$
}

\begin{abstract}
This study aimed at modelling the wastewater collection system in Cha-Am Municipality using PCSWMM to investigate the quantity of combined sewage delivered to the aeration lagoon treatment system (ALTS). Cha-Am is a small sea resort town in Petchaburi Province located about $175 \mathrm{~km}$ southwest of Bangkok and is facing increasing development so it is important to understand current system performance and plan for future build out. PCSWMM was calibrated using observed ALTS inflow data for the period 15 June to 20 July 2015. The model was validated using observed ALTS inflow data for the periods 19 July to 20 October 2015 and 1 October to 31 December 2015, respectively. The 1:1 lines between modeled and observed peak flow and event volume for the calibration events qualitatively showed good correspondence. The $r^{2}$ values between modeled and observed peak flow (99\%) and event volume (89\%) also were strong.
\end{abstract}

Keywords - Combined sewer system, Mathematical modelling, PCSWMM, Wastewater collection system.

\section{INTRODUCTION}

C HA-AM is a small sea resort town on the west coast along the Gulf of Thailand in Petchaburi Province, situated approximately $175 \mathrm{~km}$ southwest of Bangkok and about 25 $\mathrm{km}$ north of Hua Hin, another popular sea resort town. It has a population of approximately 53,891 people and roughly 14,855 households [1]. The population of Cha-Am increases with the increasing number of foreign tourists who like to stay for several weeks or even months at a time. The population of the town also increases at other times of the year, especially on weekends as tourists from Bangkok and other districts visit Cha-Am. Substantial increase in the population of the town is usually observed from September to December when the weather tends to be a little cooler [2].

Population growth in any town results in increased wastewater production, possibly leading to the situation where the receiving water bodies are progressively less able to absorb pollution loads of with/without treatment effluents. This presents challenges to the town planners and engineers who design, maintain, and operate wastewater management systems

Thawtar Htun ${ }^{1}$ is with the Department of Civil and Environmental Engineering, Faculty of Engineering, Mahidol University, Thailand.

Kim N. Irvine ${ }^{2}$ is with the National Institute of Education and Nanyang Environment and Water Research Institute, Nanyang Technological University, Singapore

Ranjna Jindal ${ }^{3}$ is with the Department of Civil and Environmental Engineering, Faculty of Engineering, Mahidol University, Thailand.
[3]. The quality and quantity of wastewater in the collection system will affect the treatment efficiency of the wastewater treatment plant. Moreover, if the wastewater overflows onto roads and public and/or private property and/or waterways this will lead to the deterioration of water quality in the receiving bodies, thereby increasing the risk of a public health hazard and contamination of the environment. Unfortunately, during heavy rains the wastewater treatment plants (WWTP) served by combined sewers can become hydraulically overloaded and washed out into the receiving stream causing a complete treatment system failure [3].

Models of water quantity and quality in the urban drainage system can be used to assist in: (a) performance assessment and the required upgrades to the existing system and (b) optimal planning and design of new systems [4]-[7]. Modelling can be helpful in wastewater collection systems planning to deal with the effects of population growth and urbanization [8].

The objective of this study is to model the wastewater collection system in Cha-Am Municipality using PCSWMM modelling software to investigate the quantity of combined sewage delivered to the aeration lagoon treatment system (ALTS).

\section{II.METHODOLOGY}

\section{A. Study Area}

Cha-Am is serviced by a combined sewer system and the flow is pumped to an aerated lagoon, centralized wastewater treatment system, before it discharges to the ocean via a small stream. The combined sewer system has been in operation at Cha-Am since 2001 with the size of the pipes between $1.2 \mathrm{~m}$ to $1.5 \mathrm{~m}$ diameter. The total length of the main line and lateral lines in the collection system are approximately $11590 \mathrm{~m}$ and $4541 \mathrm{~m}$, respectively. There are three pump stations in the collection system including the main pumping station at the wastewater treatment plant, emergency pumping station, and one lifting pump station that pumps the wastewater from the beach front area to the wastewater treatment plant.

The wastewater collection system of Cha-Am collects the wastewater from the area around the municipality office and along the beach front area. The wastewater from the area around the municipality is conveyed to the WWTP by gravity while the wastewater from the beach front area is conveyed to the lifting pump station before pumping to the WWTP. The 
lifting pump station, called Jaolai pump station, has three pumps which are rated between 40.5-970 $\mathrm{m}^{3} / \mathrm{hr} / \mathrm{pump}$, approximately 1200 to $1500 \mathrm{~m}^{3} /$ day. The end point of the wastewater collection system is the WWTP which has a pumping station that includes four pumps of $3.66 \mathrm{~m}$ in diameter and the pump capacity is approximately 280 $\mathrm{m}^{3} / \mathrm{hr}$ /pump. The pumping operation of the station was controlled by an automatic float switch level.

\section{B. Model Initialization}

One of the initial project tasks was to collect, verify, organize, and digitize information on the geographic layout and physical attributes of the entire wastewater collection system. The data were used to prepare a draft layout and physical attributes of the wastewater collection system on Google Earth Pro (version 7.1.5.1557). Google Earth Pro was used to draw the draft layout of the wastewater collection system that included the location of the manholes, subcatchments, outfalls, and the pump stations. Once located in the field, the coordinates of each manhole were recorded using GPS on an iPhone 6. During these field visits, the condition of each sewer segment was checked, and information on design modifications was used to update the draft layout. Attribute information, such as pipe diameter, elevations, slope of the pipe, and pipe materials, was previously created by the Cha-Am municipality as construction drawings. Basic checks of this database were made and field inspections were used when questionable information was found.

\section{C.Data Collection}

A wastewater collection system model must be able to simulate the flow in the sewer network at all locations and times. The pragmatic approach is to load the model with the best information available, using measurements of the sewage flow at selected points in the system to calibrate [3]. The continuous daily flow data for the year 2015 were collected from the WWTP officer, Mr. Anant Bootengchan. Spot measurements of flow and depth were done in three places, which are at the inlet of WWTP, manhole near emergency pump station, and the inlet of lifting pump station, by manually using a velocity meter.

It is important to calibrate the model under wet weather conditions because these conditions are usually the most critical situation for sewer modelling, Precipitation values in one form or another also are needed. In Thailand, the Thailand Meteorological Department (TMD) is responsible for the collection of precipitation data throughout the country. These data are available on an hourly, daily, and monthly frequency for some stations and can be requested in electronic format but there are only daily rainfall data for a small town like Cha-Am. The rainfall data for the year 2015 was requested from TMD with the daily interval in millimeter at the location which is approximately at the center of the whole catchment.

\section{D.PCSWMM Model Application}

The study area (473.28 ha) was divided into 72 subcatchments for modelling purposes (Figure 1). The characteristics of each subcatchment and sewer pipes were determined through a combination of field measurement, Google Earth, design drawings, maps, and discussions with the WWTP officer. The percentage of impervious area for each subcatchment was primarily measured using Google Earth Pro and it was imported to PCSWMM.

The dry weather wastewater flow calculation was done by using a top-down approach, where the total flow to the WWTP was divided among model subcatchments based on the percent impervious of each subcatchment. Three distinct dry weather periods were chosen to calculate the average daily dry weather flow and it was distributed to a respective node for each subcatchment.

\section{Data Processing}

The surface runoff from each subcatchment is routed to a single point within the subcatchment. Through the combination of the findings from the field work, several parameters were quantified including subcatchment area, width, pervious and impervious area. Sewer lines for the model input were drawn based on the existing sewer network lines. The existing sewer network lines were constructed using $0.6 \mathrm{~m}, 0.8 \mathrm{~m}, 1 \mathrm{~m}$ and $1.2 \mathrm{~m}$ diameter concrete circular pipes and $1.2 \times 1.2 \mathrm{~m}, 1.2 \times 1.5 \mathrm{~m}$ and $1.5 \times 1.5 \mathrm{~m}$ concrete rectangular box, respectively. The main pipeline in the system conveying wastewater from south to north direction exists parallel along the beach and has variable slope between 0.0005 to 0.0017 .

\section{Surface Runoff Calculation}

PCSWMM uses a nonlinear reservoir approach to estimate surface runoff produced by rainfall over each sub-area of a subcatchment [9]. Overland flow is generated by modeling the subcatchment as a nonlinear reservoir, as sketched in Figure 2.

From conservation of mass, the net change in depth per unit of time of water stored on the land surface is simply the difference between inflow and outflow rates over the subcatchment:

$$
\frac{\partial d}{\partial t}=i-e-f-q
$$

where:

$$
\begin{aligned}
& i=\text { rate of rainfall }+ \text { snowmelt }(\mathrm{m} / \mathrm{s}) \\
& e=\text { surface evaporation rate }(\mathrm{m} / \mathrm{s}) \\
& f=\text { infiltration rate }(\mathrm{m} / \mathrm{s}) \\
& q=\text { runoff rate }(\mathrm{m} / \mathrm{s}) . \\
& \text { Note that the fluxes } i, e, f \text {, and } q \text { are expressed as flow rates } \\
& \text { per unit area }\left(\mathrm{cms} / \mathrm{m}^{2}=\mathrm{m} / \mathrm{s}\right) .
\end{aligned}
$$



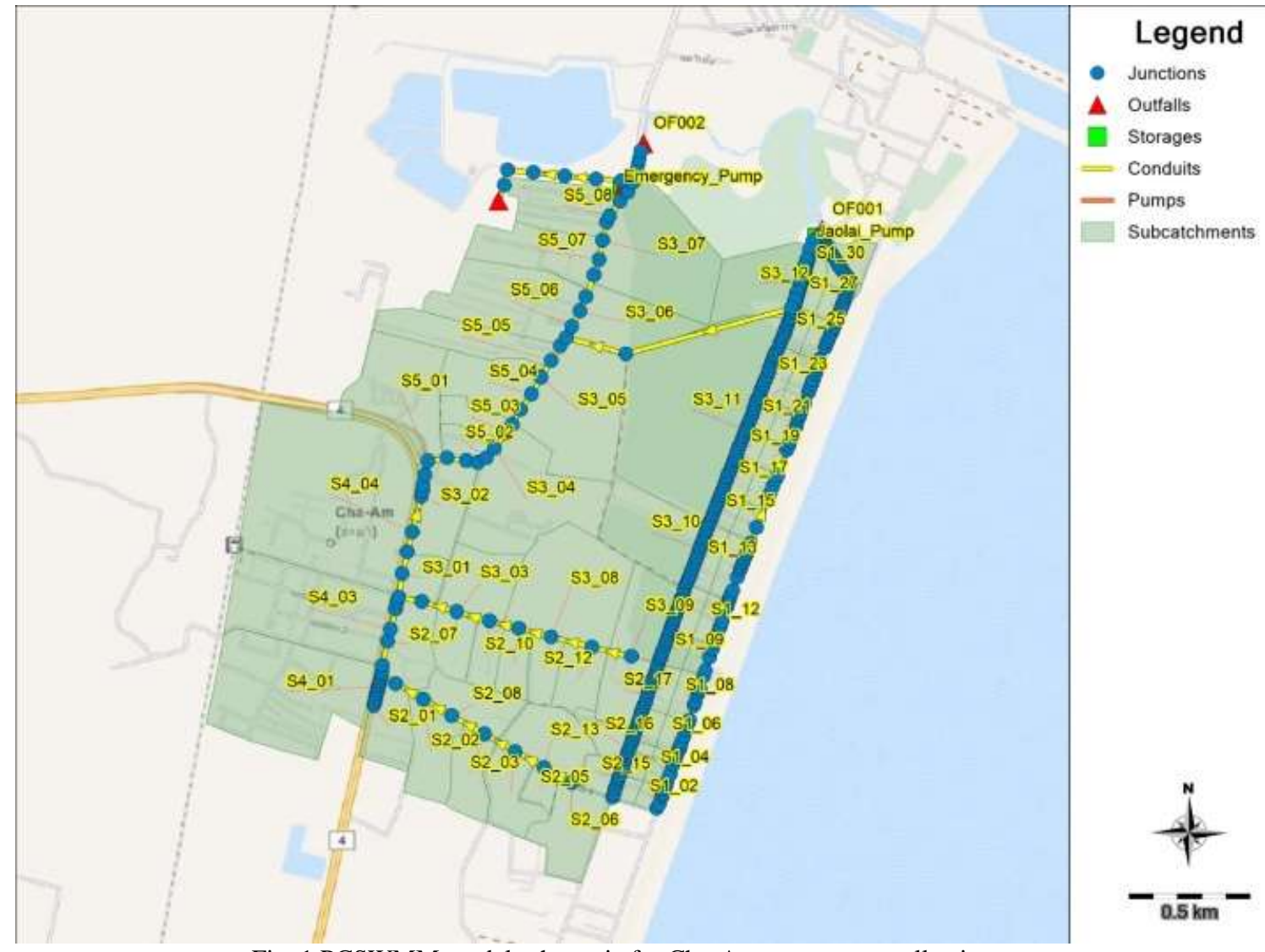

Fig. 1 PCSWMM model schematic for Cha-Am wastewater collection system

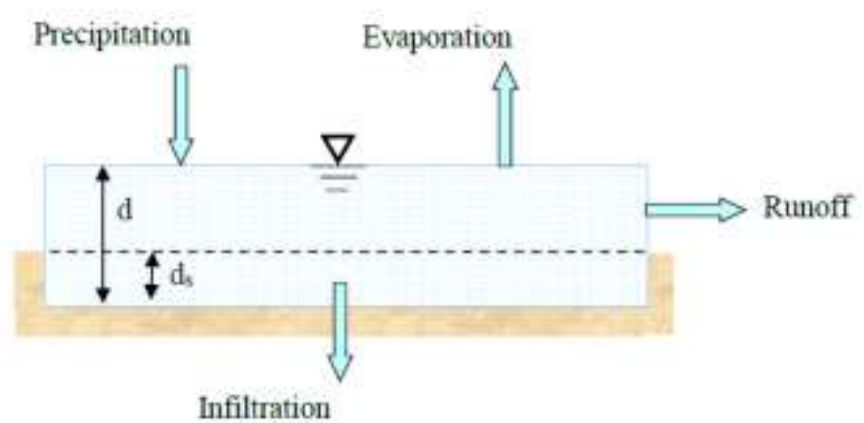

Fig. 2 Nonlinear reservoir model of a subcatchment [9]

By assuming that the overland flow across the sub-area's width is normal, the Manning equation can be used to express the runoff rate $\mathrm{q}$ as:

$$
q=Q / A=\frac{1.49 W S^{1 / 2}}{A n}\left(d-d_{s}\right)^{5 / 3}
$$

where:

$W=$ width of the subcatchment outflow face

$n=$ surface roughness coefficient

$S=$ average slope of the subcatchment $(\mathrm{m} / \mathrm{m})$

$A=$ subcatchment area $\left(\mathrm{m}^{2}\right)$

$d_{s}=$ depression storage depth $(\mathrm{m})$.

Note that no runoff occurs when $d$ is below $d_{s}$. Substituting (2) into (1) produces an ordinary non-linear differential equation that can be solved numerically for $\mathrm{d}$ over a sequence of discrete time steps given externally imposed rainfall and evaporation rates and a computed infiltration rate f. By knowing d, (2) can be evaluated to determine the runoff $q$ at each time step.

\section{Infiltration Calculation}

PCSWMM offers a choice of five different methods for computing soil infiltration rates - the Horton, Modified Horton, Green-Ampt, Modified Green-Ampt, and Curve Number models. The Green-Ampt method was chosen for use in this model because it is based on physical parameters that can be related to the site's soil type.

$$
f_{p}=K_{s}\left[1+\frac{\psi_{s} \theta_{d}}{F}\right]
$$

where:

$K_{s}=$ saturated hydraulic conductivity $(\mathrm{m} / \mathrm{s})$

$\psi_{s}=$ suction head along the wetting front $(\mathrm{m})$

$\theta_{d}=$ intial moisture deficit (m)

$\mathrm{F}=$ cumulative infiltration $(\mathrm{m} / \mathrm{s})$.

The dynamic wave routing option was chosen to reduce flow continuity error. Dynamic wave routing solves the complete one-dimensional Saint Venant flow equations that consist of the continuity and momentum equations for conduits and a volume continuity equation at nodes, and therefore produces the most theoretically accurate results for pumping and surcharging conditions. PCSWMM routing calculations were done in 5 second time intervals, with output reporting done every 30 minutes as well as averaging over an entire simulation period. 


\section{RESULTS AND DISCUSSION}

Model results for the period 15 June to 20 July 2015 are shown in Figure 3. The modelled flows are compared to the observed inflow to the WWTP, based on the PCSWMM model result. In the figure, the model accurately predicted the peak values for the three storm events. The total flow volume for these three storms collectively also was similar between the model result and the observed with the value of $163100 \mathrm{~m}^{3}$ and $164000 \mathrm{~m}^{3}$, respectively.

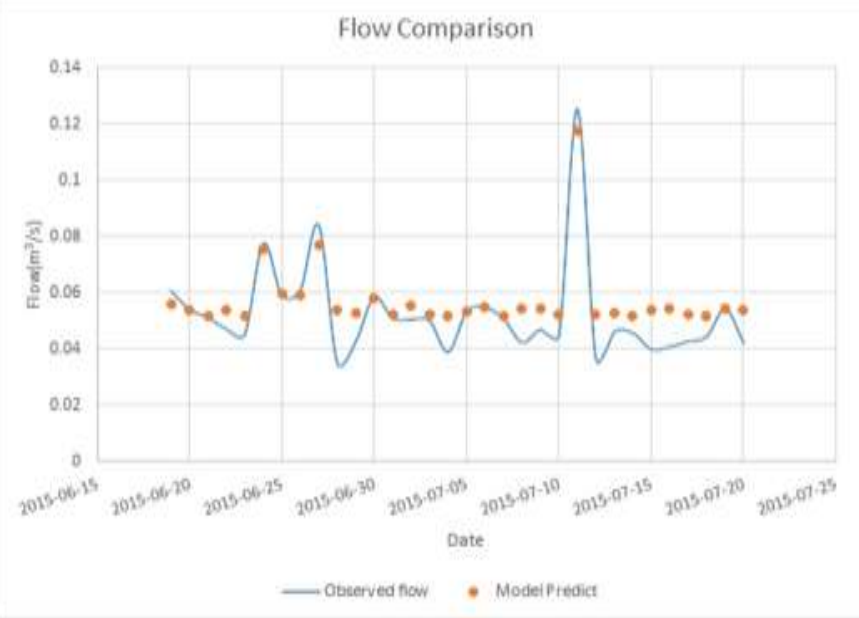

Fig. 3 Flow comparison between model predict and observed

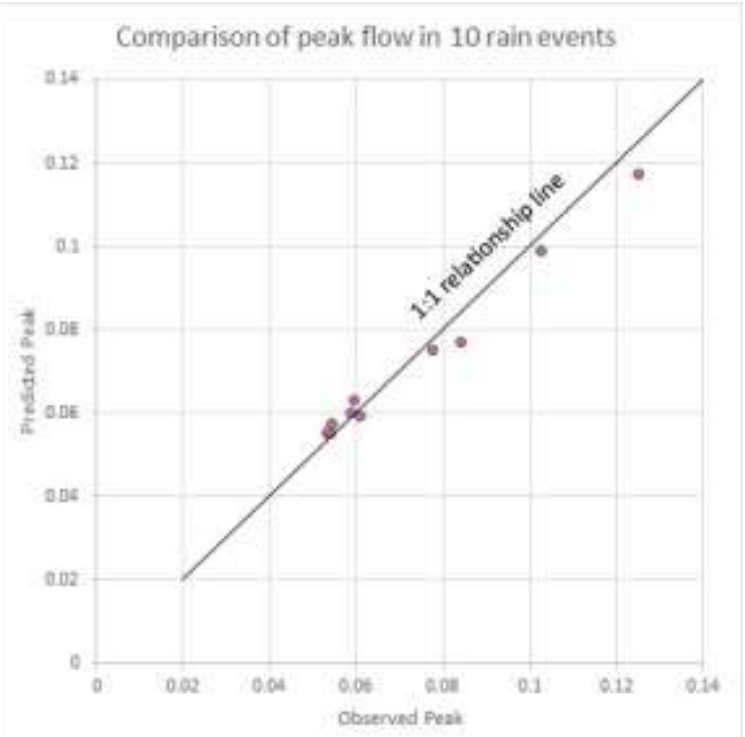

Fig. 4 Comparison of modelled and observed peak flow in 10 rain events

A comparison between the modelled and observed peak flow for ten storm events also showed good correspondence with the $\mathrm{r}^{2}$ value of 0.99 (Figure 4).

A comparison of the modelled and observed event volume that entered the WWTP between 15 June and 20 July 2015 also showed good correspondence with the $r^{2}$ value of 0.89 (Figure 5). There was a slight bias towards model underestimation for the smaller events.

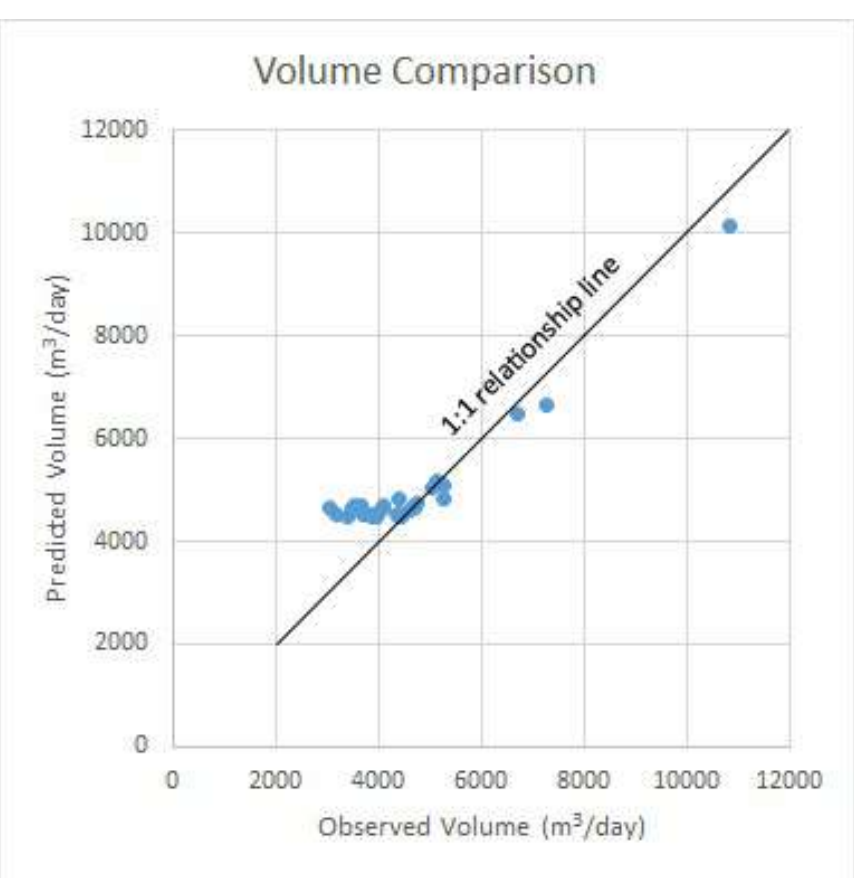

Fig. 5 Volume comparison between model predict and observed

\section{CONCLUSIONS}

PCSWMM has been developed to investigate the quantity of combined sewage flow associated with the current wastewater collection for Cha-Am, Thailand. The model results were similar to the observed flow data. The calibrated model can now be used with some confidence to obtain additional information about the quantity of wastewater flow in the collection system and fluctuations in the inflow to the Cha-Am municipality wastewater treatment system that may be useful to town planners and designers. The model can also help to evaluate future expansion of the sewer network by analyzing available capacity and identifying locations for new drainage construction to offset new development. The next step in this research will be to link the collection system with the ALTS system that has been modelled separately in PCSWMM [10] and explore the impact of future development scenarios on treatment efficiency.

\section{ACKNOWLEDGMENT}

We are grateful for the scholarship from Norwegian Foreign Affaire to support this research. We are also thankful to Computational Hydraulics Int. for the software support through the CHI University Grant Program. Mr. Anant Bootengchan provided flow data for the ALTS and was a remarkable source of information regarding system operation.

\section{REFERENCES}

[1] Census. 2010. Population and Housing Census 2010. Retrieved April 10, 2015 from

http://web.nso.go.th/en/census/poph/2010/cen_poph_10_cen.htm

[2] Thai Visa Cha Am. 2015. Cha Am Population and Size. Retrieved April 10, 2015 from http://cha-am.thaivisa.com/size-location-and-population

[3] Walski TM, Barnard TE, Harold E, Merritt LB, Walker N, Whitman BE. 2007. Introduction to Wastewater Collection System Modeling. In 
WASTEWATER COLLECTION SYSTEM MODELING AND DESIGN (p. 1). Waterbury, CT USA: HAESTAD PRESS.

[4] Bauwens W, Vanrolleghem P, Smeets M. 1996. An evaluation of the efficiency of the combined sewer-wastewater treatment system under transient conditions. Water Sci Technol ;33(2):199-208. https://doi.org/10.1016/0273-1223(96)00201-6

[5] Benedetti L, Bixio D, Vanrolleghem PA. 2006. Assessment of WWTP design and upgrade options: balancing costs and risks of standards' exceedance. Water Sci Technol ;54(6):371-8. https://doi.org/10.2166/wst.2006.571

[6] Gamerith V, Gruber G, Muschalla D. 2011. Single- and multievent optimization in combined sewer flow and water quality model calibration. J Environ Eng ; 137(7):551-8. https://doi.org/10.1061/(ASCE)EE.1943-7870.0000356

[7] Vollertsen J, Hvitved-Jacobsen T, Ujang Z, Talib SA. 2002. Integrated design of sewers and wastewater treatment plants. Water Sci Technol ;46(9):11-20.

[8] Jang, S., Cho, M., Yoon, J., Yoon, Y., Kim, S., Kim, G., Aksoy, H. 2007. Using SWMM as a tool for hydrologic impact assessment. Desalination, 212(1-3), 344-356. https://doi.org/10.1016/j.desal.2007.05.005

[9] Chen, C.W. and Shubinski, R.P. 1971. "Computer Simulation of Urban Storm Water Runoff." Journal of the Hydraulics Division. ASCE, 97(2):289-301.

[10] Bowmick, A., Irvine K.N., \& Jindal, R. (submitted). Mathematical Modelling of Effluent Quality of Cha-Am Municipality Wastewater Treatment Pond System Using PCSWMM. Journal of Water Management Modelling 